\title{
Characterisation of the high strain rate properties of Advanced High Strength Steels
}

\author{
J. Van Slycken ${ }^{1}$, P. Verleysen ${ }^{1}$, J. Degrieck ${ }^{1} \&$ J. Bouquerel $^{2}$ \\ ${ }^{I}$ Department of Mechanical Construction and Production, \\ Faculty of Engineering, Ghent University, Belgium \\ ${ }^{2}$ Department of Metallurgy and Materials Science, \\ Faculty of Engineering, Ghent University, Belgium
}

\begin{abstract}
In the automotive industry a lot of energy is put into the development of lightweight auto body structures that are able to outperform the classic structures. For these purposes tremendous advances have been made in the field of multi-phase steels. Complex steel grades have been developed with exceptional mechanical properties: they combine high strength values (yield strength, tensile strength, etc.) with an excellent ductility. TRIP steels (TRansformation Induced Plasticity steels) show these properties pre-eminently. To guarantee a controlled dissipation of the energy released during a crash, knowledge and understanding of the impact-dynamic material properties is essential. In this paper the results are presented of an extensive experimental program to investigate the strain rate dependent mechanical properties of different TRIP steels. The influence of different alloying types (Al, Si, SiAl, etc.) on the static and dynamic stress-strain behaviour is investigated. A split Hopkinson tensile bar set-up was used for the experiments. Microstructural observation techniques such as different optical methods, SEM and XRD were used to reveal the mechanisms governing the observed high strain rate behaviour. From the results it is clear that the excellent mechanical properties are not only preserved at higher strain rates, but still improve. The influence of the alloying elements is comparable in the static and dynamic case: aluminium tends to increase the elongation level of the material, whereas silicon improves the stress that is achieved.
\end{abstract}

Keywords: high strain rate behaviour, split Hopkinson tensile bar, TRIP steel, alloying elements. 


\section{Introduction}

Engineered steels provide automotive designers and manufacturers with the unique option to combine lightweight design with the traditional advantages of steel: low cost and eco-efficiency. Under the impulse of several steel-auto partnerships, including the Ultra Light Steel Auto Body (ULSAB) program, new types of high-strength steel, called Advanced High-Strength Steels (AHSS) (Bleck [1]), are engineered to complete the traditional steel grades. In the ULSAB-Advanced Vehicle Concept (AVC) program, the need to reduce the added mass which is required to satisfy future safety mandates presents the opportunity to apply these newer types of high-strength steels in the design of an efficient lightweight body structure. Members of the AHSS family include Dual Phase (DP), Transformation Induced Plasticity (TRIP), Complex Phase (CP) and Martensite Steels (MS).

The low alloy TRIP steels show high strength values in combination with an excellent deformability, making them the material of choice for impactabsorbing structural parts of auto-bodies (Bleck [1]). TRIP steel has a microstructure of soft ferrite $(\alpha)$ grains with bainite $\left(\alpha_{B}\right)$ and retained austenite $(\gamma)$ (figure 1). The retained austenite transforms into martensite $\left(\alpha^{\prime}\right)$ during deformation. The hard martensite delays the onset of necking leading to high total elongation values and high crash energy absorption. TRIP steels can therefore be engineered or tailored to provide excellent formability for manufacturing complex parts. In addition, these steels can be designed into the automotive body structure to offer excellent crash energy absorption.

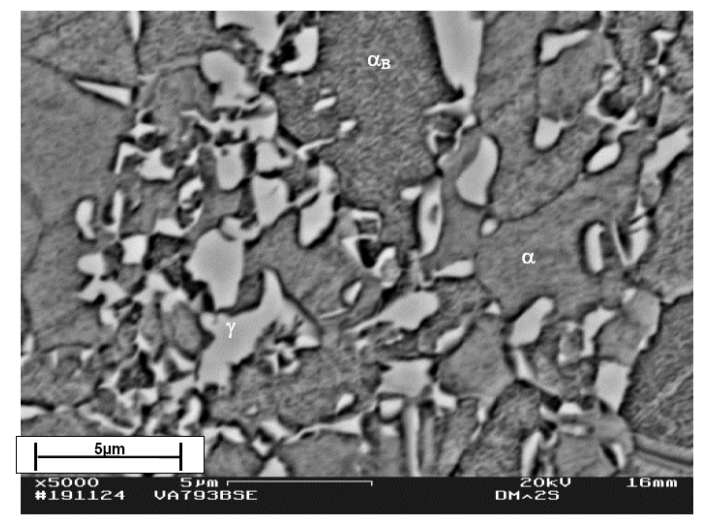

Figure 1: $\quad$ SEM-micrograph showing the multiphase microstructure of a nondeformed CMnAl-TRIP steel (magnification: x 5000).

The need for more optimized crashworthiness analysis in the automotive industry makes high strain rate tensile testing of sheet steels very important. It is well known that steels display positive strain rate performance, i.e. at the higher rates of strain which are typically associated with crash events, steels have higher 
strengths and consequently higher crash energy absorption. Different types of testing techniques have been used to generate data under these dynamic conditions, each serving a specific range of strain rates. One of the most commonly used setups is a split Hopkinson bar setup. Mostly, a pressure apparatus is used to obtain the dynamic parameters (Davies and Hunter [2]), a tensile setup is however preferred for the testing of sheet metals. Stress-strain curves at strain rates varying from 500 to $2000 \mathrm{~s}^{-1}$ can be obtained with the tensile setup developed at Ghent University.

The behaviour of steels during high strain rate loading is the result of the interaction between two opposing processes: strain rate hardening and thermal softening, which is due to adiabatic heating during deformation. In the case of TRIP steels, thermal softening also affects the $\gamma$ - $\alpha$ ' transformation: the increased temperature reduces the transformation rate. This paper presents the results of an extensive experimental program, which is set up to assess the dynamic mechanical behaviour of TRIP steels. Special attention is paid to the influence of the different alloying elements in TRIP steels on the stability of the austenite phase and thus on the transformation in the material.

\section{Materials and methods}

\subsection{Materials}

A key parameter for the TRIP effect is the stability of the meta-stable austenite which is mainly determined by the austenite particle size and the composition, especially the carbon content is an important parameter (Itami et al. [3]). Alloying elements such as silicon, aluminium and phosphor in TRIP steels principally added to inhibit carbide precipitation during the second stage isothermal holding temperature in the production process of TRIP steels - also significantly influence the thermodynamic stability of the austenite phase. The influence of the alloying elements is assessed by the study of four different TRIP steel grades: CMnAl-, CMnSi-, CMnSiAl- and CMnSiAlP-TRIP. Specific care was taken to keep the same carbon content for each steel grade. Table 1 lists the composition of the low alloy TRIP steels.

Table 1: Chemical composition of the investigated TRIP steel grades (in weight percent).

\begin{tabular}{|c|c|c|c|c|c|}
\hline Steel grade & $\mathrm{C}$ & $\mathrm{Mn}$ & $\mathrm{Al}$ & $\mathrm{Si}$ & $\mathrm{P}$ \\
\hline CMnAl-TRIP & 0.24 & 1.61 & $\underline{1.54}$ & 0.091 & 0.006 \\
\hline CMnSi-TRIP & 0.25 & 1.67 & 0.78 & $\underline{1.28}$ & 0.012 \\
\hline CMnSiAl-TRIP & 0.25 & 1.70 & $\underline{0.69}$ & $\underline{0.55}$ & 0.011 \\
\hline CMnSiAlP-TRIP & 0.20 & 1.56 & $\underline{0.29}$ & $\underline{0.38}$ & $\underline{0.012}$ \\
\hline
\end{tabular}

Silicon strengthens the ferrite phase considerably, but high Si-contents results in an adherent $\mathrm{FeO} . \mathrm{SiO}_{2}$ oxide layer on the sheet surface, which generates surface defects on the hot rolled sheet and which is difficult to remove by 
pickling. Moreover, due to this oxide layer CMnSi-TRIP steels are complicated to galvanize and thus to process in continuous galvanizing lines. Therefore, $\mathrm{Al}$ has been used to replace the silicon in TRIP steels. Al increases the ductility significantly because it has a lower solid solution strengthening potential for the ferrite phase (Girault et al. [4]).

\subsection{Experimental testing procedure}

A Split Hopkinson Tensile Bar (SHTB) apparatus is used to characterize the dynamic properties of the investigated materials. It mainly consists of two bars: an input and an output bar between which a specimen of the test material is attached (figure 2). A tensile wave is produced by an impactor that is accelerated towards the anvil of the input bar. After the impact this incident wave travels along the input bar towards the specimen where it interacts with the sample and is partly reflected back into the input bar. The other part, the transmitted wave, travels along the output bar. The strain histories of the different waves (incident, reflected and transmitted wave, respectively denoted as $\left.\varepsilon_{\mathrm{i}}(\mathrm{t}), \varepsilon_{\mathrm{r}}(\mathrm{t}), \varepsilon_{\mathrm{t}}(\mathrm{t})\right)$, are recorded by means of strain gauges mounted on both bars. By adjusting the impact speed of the impactor, the strain rate can be varied.

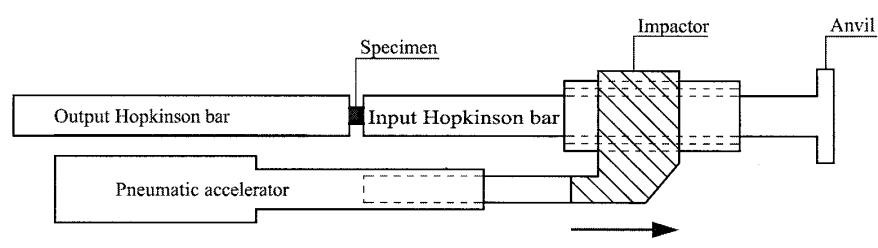

Figure 2: Schematic representation of the Split Hopkinson Tensile Bar (SHTB) set-up.

According to the one-dimensional wave theory and the assumption of a uniaxial and homogeneous stress and strain in the specimen, the stress, strain and strain rate in the specimen can be written as follows (Kolsky [5]):

$$
\begin{gathered}
\sigma(\mathrm{t})=\frac{\mathrm{E}_{\mathrm{b}} \mathrm{A}_{\mathrm{b}}}{\mathrm{A}_{\mathrm{s}}} \varepsilon_{\mathrm{t}}(\mathrm{t}), \varepsilon(\mathrm{t})=\frac{\mathrm{U}_{\mathrm{ob}}-\mathrm{U}_{\mathrm{ib}}}{\mathrm{L}_{\mathrm{s}}}=-\frac{2 \mathrm{C}_{\mathrm{b}}}{\mathrm{L}_{\mathrm{s}}} \int_{0}^{\mathrm{t}} \varepsilon_{\mathrm{r}}(\tau) \mathrm{d} \tau, \\
\dot{\varepsilon}(\mathrm{t})=\frac{\mathrm{V}_{\mathrm{ob}}-\mathrm{V}_{\mathrm{ib}}}{\mathrm{L}_{\mathrm{s}}}=-\frac{2 \mathrm{C}_{\mathrm{b}}}{\mathrm{L}_{\mathrm{s}}} \varepsilon_{\mathrm{r}}(\mathrm{t})
\end{gathered}
$$

where, $\mathrm{A}_{\mathrm{s}}$ and $\mathrm{L}_{\mathrm{s}}$ are the cross-sectional area and the length of the testing region of the specimen, respectively. $C_{b}$ is the one-dimensional elastic stress wave velocity in the input/output bar material, $A_{b}$ is the cross-section area and $E_{b}$ is Young's modulus of the input/output bar. $U_{i b}$ and $U_{o b}$ are the displacements of the specimen/input bar interface and the specimen/output bar interface, respectively. $\mathrm{V}_{\mathrm{ib}}$ and $\mathrm{V}_{\mathrm{ob}}$ are the corresponding interface velocities. 


\section{Results}

\subsection{Influence of the alloying elements}

Figure 3 shows a comparison of the engineering stress-strain curves of the different investigated steel grades at a strain rate of $\sim 1600 \mathrm{~s}^{-1}$. The four steel grades exhibit a remarkable uniform elongation despite their high strength levels. This is due to the occurrence of the strain-induced transformation and thus, to the TRIP effect. The difference in their respective strength and elongation levels can be attributed to their chemical composition. The differences in dynamic flow stress are fully consistent with the ones in the static case: silicon addition increases the strength considerably, whereas aluminium has little effect on the strength level (Girault et al. [4]) and the CMnSiAl-TRIP steel shows an intermediate behaviour. The addition of phosphor on the other hand, has limited influence on the behaviour at the early stages of deformation. When the strain increases, the strain hardening of the CMnSiAl-TRIP steel is more important than of the CMnSiAlP-TRIP, which reaches maximum stress and uniform elongation at a lower level of deformation.

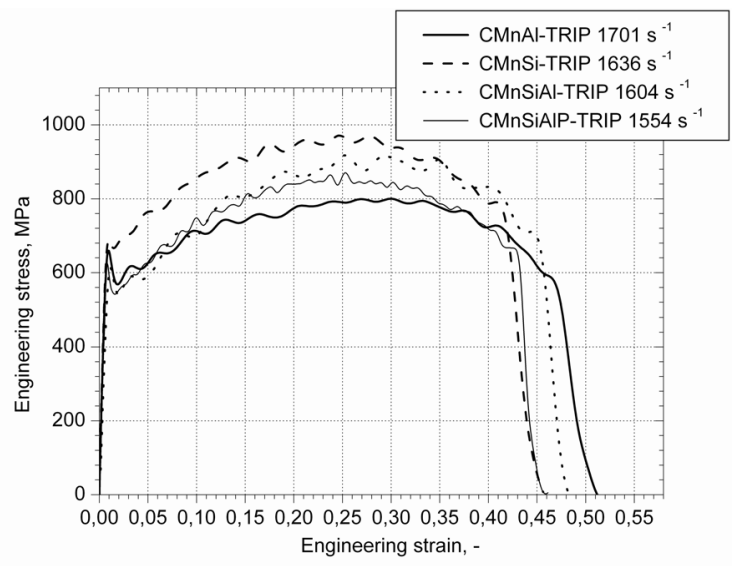

Figure 3: Comparison of the engineering stress-strain curves of the investigated steel grades at high strain rate $\left(\sim 1600 \mathrm{~s}^{-1}\right)$.

\subsection{Strain hardening}

To investigate the hardening behaviour, the strain hardening coefficient or nvalue, appearing in the Hollomon stress-strain relation of eqn (2) (Stout and Follansbee [6]) is calculated as a function of strain for the different stress-strain curves.

$$
\sigma=K \varepsilon_{p}^{n}
$$


where $\sigma$ is the true stress, $\varepsilon_{\mathrm{p}}$ the true plastic strain and $\mathrm{K}$ is a material constant. A strain window of 0.05 in which the strain hardening coefficient is averaged out, is used to minimize the effect of oscillations in the stress-strain curves. In figure 4 the evolution of the strain hardening coefficient as a function of the true strain is represented for the TRIP steels. In the early stages of deformation, the strain hardening is highest for the CMnSiAl (P)-TRIP steels, followed by the CMnSiTRIP. The TRIP steel with high aluminium content shows the lowest strain hardening in the beginning. The hardening of CMnAlSiP-TRIP begins to stabilize and in the region between 7 and $14 \%$ of true strain the hardening behaviour of $\mathrm{CMnAl}, \mathrm{CMnSi}$ and $\mathrm{CMnAlSiP}$ is similar. After approximately $14 \%$ of true strain, the strain hardening coefficient of the CMnSi-TRIP steel begins to decrease. The decrease of the strain hardening of the CMnAl- and the CMnSiAl (P)-TRIP steels begins later during the deformation. The CMnAl-TRIP steel shows a slighter decrease in strain hardening at the end of the deformation.

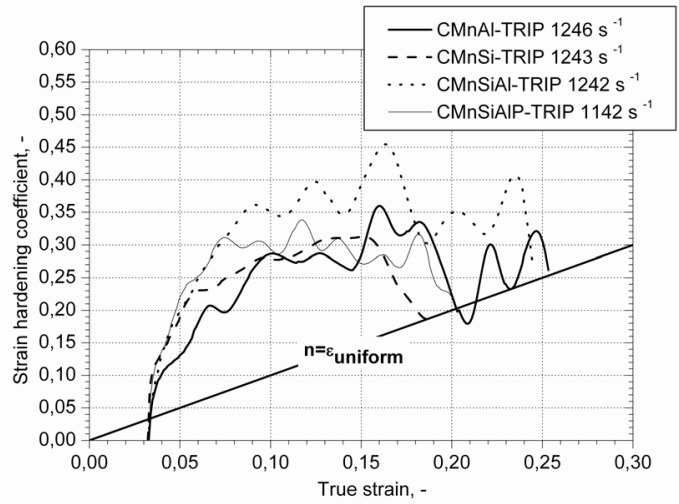

Figure 4: Comparison of the strain hardening coefficients or n-value of the investigated TRIP steel grades in function of the true strain at a strain rate of $\sim 1200 \mathrm{~s}^{-1}$.

When looking at the uniform elongation, CMnAl-TRIP steel shows the highest n-value, whereas CMnSi-TRIP steel shows the lowest. Figure 5 displays the strain hardening rate $(\mathrm{d} \sigma / \mathrm{d} \varepsilon)$ for the investigated steel grades during dynamic deformation. The strain hardening rate of ferrite is known to increase with silicon additions and to be insignificantly affected by the presence of aluminium. Accordingly, this behaviour is seen in dynamic conditions during the early stages of deformation. CMnSi-TRIP shows the highest strain hardening rate, whereas CMnAl-TRIP has the lowest values. CMnSiAl shows an intermediate behaviour. After approximately $7 \%$ of true strain, the strain hardening rate of the $\mathrm{CMnSi}$ TRIP and the CMnSiAl (P)-TRIP steels become similar. The behaviour of the CMnAl-TRIP steel shows a more constant evolution during deformation, whereas the other steel grades have a steeper decrease in strain hardening rate. 


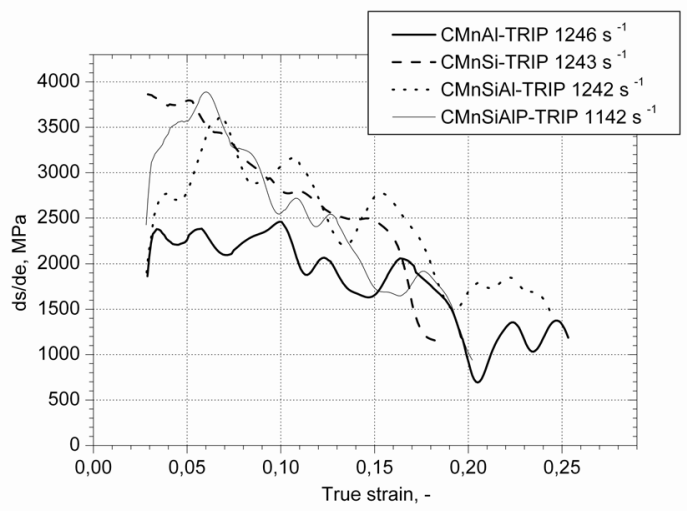

Figure 5: Comparison of the strain hardening rate $d \sigma / d \varepsilon$ of the investigated TRIP steel grades in function of the true strain at a strain rate of $\sim 1200 \mathrm{~s}^{-1}$.

\subsection{Influence of the strain rate}

In figure 6 the tensile strength in function of the strain rate is presented for the CMnAl-, CMnSi- and the CMnSiAl-TRIP steel grades. The influence of the strain rate is material dependent, but positive for both the CMnSi-TRIP steel and the CMnAl-TRIP steels: stress levels rise as the strain rate increases whereas for the CMnSiAl-TRIP this influence is limited. Quite some scatter can be noticed for the tensile strength values for the CMnSi-TRIP steel.

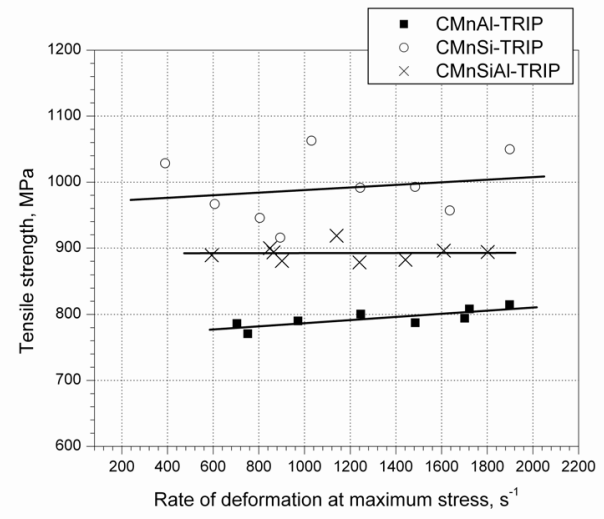

Figure 6: Tensile strength as a function of strain rate for the CMnAl-, CMnSi and the CMnSiAl-TRIP steel grades.

Different parameters can be used to evaluate the crash-resistance performance of steels. Since, for most applications, the material rarely deforms up to fracture, 
the yield stress and energy absorbed by the material at certain levels of deformation gives valuable information. In figure 7 the energy dissipated by the CMnAl-, CMnSi- and the CMnSiAl-TRIP steel at $10 \%$ strain is given as a function of the strain rate. From this figure it is clear that all steel grades exhibit a positive strain rate dependency. The CMnSi-TRIP steel shows the highest energy absorption values, the other two steel grades have similar energy absorption levels.

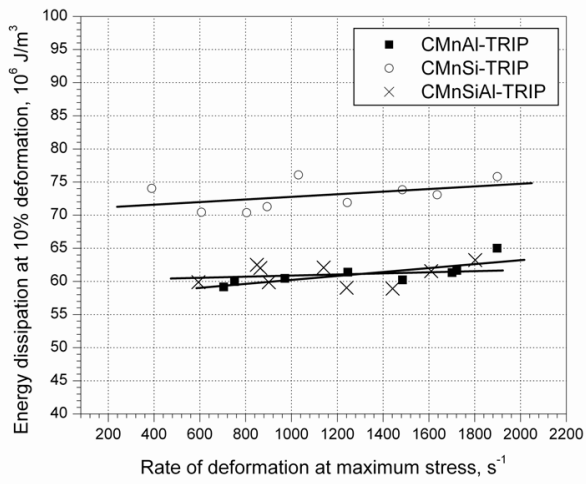

Figure 7: Energy absorption until 10\% deformation as a function of strain rate for the CMnAl-, CMnSi and the CMnSiAl-TRIP steel grades.

In dynamic conditions the strain rate has limited influence on the material properties. If these dynamic properties are compared to properties after static deformation on the other hand, an important difference can be observed. Table 2 shows the mechanical properties of the CMnAl-TRIP steel after static (strained at a constant strain rate of $10^{-4} \mathrm{~s}^{-1}$ ) and after dynamic deformation. An important increase in both yield and tensile strength can be noticed when comparing static to dynamic conditions. The uniform elongation however shows limited changes, as well as the energy dissipation until $10 \%$ deformation.

Table 2: $\quad$ Mechanical properties of CMnAl-TRIP steel in static and dynamic conditions.

\begin{tabular}{|c|c|c|c|c|}
\hline & $\begin{array}{c}\text { Upper yield } \\
\text { strength, } \\
\mathrm{MPa}\end{array}$ & $\begin{array}{c}\text { Tensile } \\
\text { strength, } \\
\mathrm{MPa}\end{array}$ & $\begin{array}{c}\text { Uniform } \\
\text { elongation, - }\end{array}$ & $\begin{array}{c}\text { Energy } \\
\text { dissipation at } \\
10 \% \\
\text { deformation, } \\
10^{6} \mathrm{~J} / \mathrm{m}^{3}\end{array}$ \\
\hline Static & 506 & 689 & 0,265 & 55,91 \\
\hline $704 \mathrm{~s}^{-1}$ & 622 & 786 & 0,264 & 59,16 \\
\hline $1246 \mathrm{~s}^{-1}$ & 646 & 800 & 0,301 & 61,39 \\
\hline $1898 \mathrm{~s}^{-1}$ & 672 & 814 & 0,252 & 64,99 \\
\hline
\end{tabular}


This can be explained when looking at the X-ray diffraction (XRD) patterns in order to reveal the mechanisms governing the complex mechanical behaviour. In figure $8 \mathrm{XRD}$ patterns of non-deformed specimens are compared with patterns of specimens after static and dynamic tests. The measurements are performed on a Siemens D5000 diffractometer. Only the ferrite (b.c.c.) and austenite (f.c.c.) peaks are considered in the measurements. Diffractograms were obtained in the $19^{\circ}-40^{\circ} 2 \theta$-range using a filtered molybdenum $\mathrm{K} \alpha$ radiation.

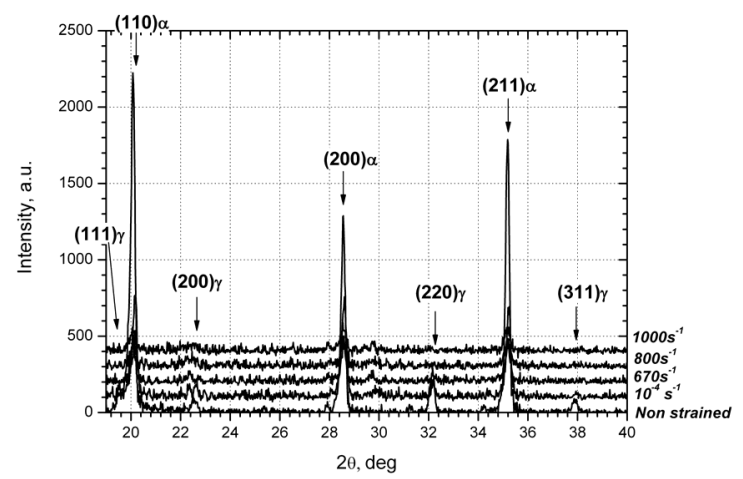

Figure 8: $\quad$ XRD pattern for the CMnAl-TRIP steel, 2 $\theta$-range between $19^{\circ}$ and $40^{\circ}$.

The diffractogram of the non-strained sample presents an initial amount of $12 \%$ of retained austenite. After both static and dynamic tensile tests, no $(220)_{\gamma}$ austenite peaks, except the $(200)_{\gamma}$ one, are present. In the dynamic tests, no austenite was expected because of the importance of the adiabatic heating during deformation. The temperature in the specimen is expected to reach, at the end of the test, about $90-100^{\circ} \mathrm{C}$. The temperature increase inhibits the austenite to martensite transformation kinetic (Samek et al. [7]).

\section{Conclusions}

Results are presented of an extensive study of the strain rate dependent behaviour of TRIP steels. These materials combine high strength with high ductility and offer therefore an excellent crash energy absorption potential. Split Hopkinson tensile bar tests are performed to obtain the stress-strain curves at higher strain rates. The influence of the strain rate on the behaviour is especially important when comparing static with dynamic testing conditions. The amount of austenite that is transformed to martensite and the adiabatic heating during dynamic deformation plays an important role. Special attention is paid to the influence of alloying elements such as $\mathrm{Al}, \mathrm{Si}$ and $\mathrm{P}$ on the dynamic behaviour of TRIP steels. As in the static case, silicon contributes to a significant solid solution strengthening of the ferrite matrix. TRIP steels with high silicon content 
show therefore high strength levels. TRIP steels mainly alloyed with aluminium on the other hand exhibit lower strength values but higher elongation levels. The work hardening of the latter steel grade is more constant during deformation, whereas TRIP steels with high silicon content show higher work hardening. These properties can further be used to develop several material models. The strain rate dependent behaviour cannot be described in a general way and various types of constitutive relations have been proposed. The validation of these models can be used for crashworthiness analysis in the automotive industry.

\section{References}

[1] Bleck, W., Using the TRIP effect - the dawn of a promising group of cold formable steels. Proceedings of the International Conference on TRIPAided High Strength Ferrous Alloys, ed. B. C. De Cooman, pp. 13-24, 2002.

[2] Davies, E. D. H. \& Hunter, S. C., The dynamic compression testing of solids by the method of the split Hopkinson pressure bar. J. Mech. Phys. Solids, 11, pp. 155-179, 1963.

[3] Itami, A., Takahashi, M. \& Ushioda, K., Plastic Stability of Retained Austenite in the Cold-Rolled 0.14-Percent-C-1.9-Percent-Si-1.7-PercentMn Sheet Steel. Isij International, 35(9), pp. 1121-1127, 1995.

[4] Girault, E., Mertens, A., Jacques, P., Houbaert, Y., Verlinden, B. \& Van Humbeeck, J., Comparison of the effects of silicon and aluminium on the tensile behaviour of multiphase TRIP-assisted steels. Scripta Materialia, 44, pp. 885-892, 2001.

[5] Kolsky, H., An investigation of mechanical properties of materials at very high strain rates of loading. Proc Phys Soc Lond Sec B, 62, pp. 676-700, 1949.

[6] Stout, M. G. \& Follansbee, P. S., Strain rate sensitivity, strain hardening, and yield behavior of 304L stainless steel. Journal of Engineering Materials and Technology - Transactions of the ASME, 108(4), pp. 344353, 1986.

[7] Samek, L., De Cooman, B. C., Van Slycken, J., Verleysen, P. \& Degrieck, J., Physical Metallurgy of Multi-Phase Steel for Improved Passenger Car Crash-Worthiness. Steel Research International, 75(11), pp. 716-723, 2004. 